\title{
La place du transport de denrées agricoles dans le cycle biogéochimique de l'azote en France : un aspect de la spécialisation des territoires
}

\author{
Julia Le Noë ${ }^{1, *}$, Gilles Billen ${ }^{1}$, Luis Lassaletta ${ }^{1}$, Marie Silvestre ${ }^{2}$ et Josette Garnier ${ }^{1}$ \\ ${ }^{1}$ UPMC, UMR-7619 Metis, 4, place Jussieu, 75005 Paris, France \\ 2 CNRS, FR-3020 Fédération Île-de-France de Recherche sur l'Environnement, 4, place Jussieu, 75005 Paris, France
}

\begin{abstract}
Résumé - L'agriculture française, agronomiquement et économiquement très performante, est responsable d'importantes pertes d'azote vers l'hydrosphère et l'atmosphère, provoquant de graves problèmes environnementaux. À partir de l'analyse de la base de données SitraM sur les transports de marchandises entre départements et avec l'étranger, un bilan des échanges de denrées agricoles, exprimés en flux d'azote protéique contenu, a été établi pour sept groupes de produits agricoles. Les 95 départements français ont été regroupés en 33 territoires agricoles, définis selon leur proximité géographique et la similitude de leur système de production. Les résultats montrent l'ampleur de la mobilité commerciale des denrées agricoles. Les échanges entre territoires et avec l'étranger en 2006 représentent 1,6 fois la production agricole nationale. Globalement, la France apparaît comme exportatrice nette de protéines avec l'étranger, important 284 kilotonne d'azote par an (ktN/an) d'aliments pour bétail et exportant $390 \mathrm{ktN} / \mathrm{an}$ principalement sous forme de céréales. L'analyse révèle l'extrême spécialisation de la plupart des territoires, soit vers les grandes cultures, soit vers l'élevage, et fait apparaître cinq grands ensembles de territoires en fonction de l'ampleur et de la destination de leurs échanges commerciaux dominants. La maîtrise du cycle de l'azote et de ses perturbations ne saurait faire l'économie d'une prise en compte des flux commerciaux de denrées agricoles.
\end{abstract}

Mots clés : cycle de l'azote / protéine / transport / spécialisation de la production / commerce agricole

\begin{abstract}
Importance of agricultural transport in the biogeochemical cycle of nitrogen in France: insight into territorial production specialization. The French agriculture, agronomically and economically very efficient, is responsible for significant nitrogen losses to the hydrosystems and the atmosphere, causing severe environmental damages. Based on the analysis of the SitraM database on commodity transport between French administrative departments and with foreign countries, a budget of agricultural goods has been established, in terms of imbedded protein- $\mathrm{N}$ fluxes, for seven groups of agricultural commodities. The 95 French departments were grouped into 33 agricultural territories defined according to their geographical proximity and the similarity of their production system. The results show the magnitude of commercial mobility of agricultural goods. Trade exchanges between territories and with foreign countries in 2006 amount to 1.6 fold the national production. Overall, France appears as net exporter of proteins with foreign countries, importing $284 \mathrm{ktonN} / \mathrm{yr}$ of feed and exporting $390 \mathrm{ktonN} / \mathrm{yr}$ mostly as cereals. The analysis reveals the extreme specialisation of many territories into either cash crop or livestock farming, and allows distinguishing five major territorial ensembles on the basis of the magnitude and destination of their food and feed exchanges. Controlling the nitrogen cycle and its perturbations by agriculture requires taking into account trade fluxes of agricultural commodities.
\end{abstract}

Keywords: nitrogen cycle / protein / transport / production specialization / agricultural trade

\section{Introduction}

Aux premiers rangs de l'Union européenne, l'agriculture française, agronomiquement et économiquement très

\footnotetext{
$\overline{\text { *Auteur de correspondance }}$ : julia.le_noe@upmc.fr
}

performante, génère un excédent de balance commerciale nationale grâce à ses exportations sur les marchés européens et mondiaux (Desriers, 2007). Sur le plan environnemental cependant, le modèle sur lequel est fondée la réussite économique de l'agriculture française est celui d'une agriculture régionalement très spécialisée et très consommatrice d'intrants 
industriels (engrais et pesticides), ce qui soulève beaucoup de questions en matière de durabilité environnementale. En particulier, l'agriculture est responsable d'une contamination généralisée de l'environnement par l'azote, donnant lieu à la fermeture de nombreux captages d'eau potable ( 878 captages abandonnés en France pour cause de pollution agricole diffuse entre 1998 et 2008, Secrétariat d'État à la Santé, 2012). D'une manière générale, les excès d'azote sont reconnus comme à l'origine d'une eutrophisation côtière préoccupante, de retombées atmosphériques d'azote menaçant la biodiversité des sites naturels, de la génération de particules fines préjudiciables à la qualité de l'air, ainsi que d'un accroissement de la teneur de l'atmosphère en $\mathrm{N}_{2} \mathrm{O}$, gaz à effet de serre actif aussi dans la destruction de la couche d'ozone (Sutton et al., 2011).

L'approche que propose la biogéochimie (au sens de l'analyse en termes de flux de matière et d'énergie du fonctionnement des systèmes complexes formés par les sociétés humaines et leur environnement, comme proposé par exemple par Billen et al., 2007), permet de produire un diagnostic d'ensemble du rôle de l'agriculture dans ce qu'il est convenu d'appeler la cascade de l'azote (Billen et al., 2013a, 2013b; Galloway et al., 2003, 2008). Une telle approche a déjà été proposée pour examiner, à l'échelle mondiale, les interdépendances agro-alimentaires entre 12 grandes régions (Billen et al., 2014). À cette échelle, l'analyse des flux commerciaux de protéines contenues dans les denrées agricoles, à partir de la base de données du commerce international de la FAO, montre une spécialisation internationale très accentuée, où un petit nombre de pays exportateurs (Brésil, Argentine, Amérique du Nord) assure les besoins en alimentation animale d'un grand nombre de pays déficitaires (Burke et al., 2009; Lassaletta et al., 2014a, 2014b ; MacDonald et al., 2015; Naylor et al., 2005). Cette déconnexion à l'échelle internationale de la production et de la consommation alimentaire génère une perte d'efficience de l'utilisation d'azote (Bai et al., 2014 ; Billen et al., 2015) et des émissions supplémentaires d'azote dans l'environnement (Caro et al., 2014 ; Lassaletta et al., 2014c). L'application de cette démarche à l'agriculture nationale est paradoxalement plus difficile, à cause de l'absence de données sur les échanges intranationaux de produits agricoles. Pourtant, les échanges de marchandises entre départements français sont recensés depuis plusieurs décennies dans la base SitraM, établie par les services ministériels en charge de la gestion des transports. Cette base n'a que rarement été exploitée dans le cadre d'études scientifiques sur la structure du système agricole. Elle a servi cependant à la définition des aires d'approvisionnement alimentaire de la métropole parisienne (Billen et al., 2009). L'objectif de cet article est de montrer que son analyse systématique permet de mettre en lumière certaines caractéristiques de l'agriculture française et de sa spécialisation régionale. Nous présentons ici une description complète des flux de denrées agricoles entre départements français, exprimés par leur contenu en protéines, une unité générique qui permet de les comparer entre eux et avec les flux majeurs de la cascade de l'azote induite par l'agriculture. Cette analyse débouche sur une géographie nouvelle qui met l'accent sur la spécialisation à l'export des régions agricoles françaises, qu'elle permet de quantifier en termes de flux d'azote, éclairant le fonctionnement du système agro-alimentaire national sous un angle inhabituel.

\section{Méthodes}

\subsection{La base SitraM}

La base de données SitraM (Système d'information sur le transport des marchandises), gérée par le Service de l'observation et des statistiques (SOeS) du ministère de l'Écologie, du Développement Durable et de l'Énergie (http://www.statisti ques.developpement-durable.gouv.fr/sources-methodes/), répertorie annuellement depuis 1974 les transports de marchandises entre départements français par route (enquête TRM), par rail (données SNCF), par voies navigables (données VNF), ainsi que les échanges avec les pays extérieurs (données des Douanes). Pour chacun de ces modes d'échanges, renseignés en valeur et en tonnage par lieu de déchargement et de dernier chargement, la base de données distingue les marchandises selon la Nomenclature pour les statistiques des transports (NST) qui comporte 176 postes dont 50 relatifs aux produits agricoles ou alimentaires. La présente étude se base sur les données de l'année 2006, la plus récente disponible avec ce degré de détail.

\subsection{La base Agreste}

La base Agreste du ministère de l'Agriculture (www. agreste.agriculture.gouv.fr/) fournit en ligne toutes les données de production agricole annuelle (animaux et végétaux en tonnes de produits récoltés) par département. Des données similaires sont disponibles pour les pays étrangers dans la base FAOstat (www.faostat.fao.org/). Si la liste des produits renseignés n'est pas tout à fait identique entre cette source et les postes de la NST, une équivalence a été obtenue par regroupements de produits (voir plus loin).

\subsection{Le logiciel AmstraM}

Un logiciel d'interrogation automatisée des bases SitraM et Agreste a été mis au point par Silvestre et al. (2015). Le principe en est le suivant (Billen et al., 2009).

La base SitraM peut être vue comme un ensemble de matrices $[F(d, o)]$ relatives à chaque produit, indiquant les flux de transport entre le lieu de leur dernier chargement (origine, o) (département français ou pays étranger) et leur destination (d). En tout, chaque matrice comprend 306 lignes et colonnes (95 départements et 211 pays).

Les flux de transport interne $F(i, i)$ n'ont pas de signification et ne sont pas à prendre en considération. Nous les remplaçons par les flux de production interne fournis par la base Agreste (et par la base FAOstat pour les pays étrangers). Nous appellerons $\left[F^{*}(d, o)\right]$ la matrice résultant de cette substitution, et qui intègre donc les données de production locale pour le produit considéré.

Nous ferons l'hypothèse que la répartition par origine de la consommation finale dans un territoire est identique à celle de la somme des importations et des productions internes de ce territoire, même si une part importante de ce qui est importé est réexportée. Cette hypothèse de " mélange parfait » revient à ignorer toute préférence de provenance tant de la consommation que de l'exportation sur l'ensemble de l'offre déjà acheminée dans le territoire. 
Tableau 1. Teneur en azote protéique des principales denrées alimentaires renseignées dans la base SitraM, et son intervalle de variation (source : Lassaletta et al., 2014a).

Table 1. Protein-nitrogen content of the main agricultural commodities in the SitraM data basis and variation interval (source: Lassaletta et al., 2014a).

\begin{tabular}{|c|c|c|c|}
\hline$\left(\mathrm{N}^{\mathrm{o}} \mathrm{NST}\right)$ & Denrée agricole & Teneur en $\mathrm{N}(\%)^{\mathrm{a}}$ & Intervalle de variation $(\%)^{b}$ \\
\hline 011-019 & Céréales (hors maïs) & 1,8 & $1,5-2,1$ \\
\hline 015 & Maïs & 1,5 & $1,36-1,56$ \\
\hline 020 & Pommes de terre & 0,3 & $0,26-0,33$ \\
\hline 167 & Houblon & 0,4 & \\
\hline 060 & Betteraves & 0,25 & $0,23-0,27$ \\
\hline 166 & Préparations et conserves à base de légumes & 0,1 & $0,1-0,2$ \\
\hline 031 & Agrumes & 0,1 & \\
\hline 035 & Autres fruits et noix frais & 0,1 & $0,1-2,9$ \\
\hline 164 & Fruits congelés, séchés, en préparations & 0,1 & $0,1-0,2$ \\
\hline 171 & Paille, foin, balles de céréales & 0,8 & $0,4-0,9$ \\
\hline 172 & Tourteaux d'oléo-protéagineux & 7,0 & $6,5-7,0$ \\
\hline 141,147 & Viande & 3,4 & $1,7-3,1$ \\
\hline 143 & Lait frais & 0,5 & $0,5-0,9$ \\
\hline 144 & Fromage et autres produits laitiers & 3,0 & $2,6-4,0$ \\
\hline 146 & Eufs & 2,1 & $1,7-2,2$ \\
\hline
\end{tabular}

NST : Nomenclature pour les statistiques des transports.

${ }^{a}$ Valeur utilisée par le logiciel AmstraM, correspondant au produit dominant, ou à la moyenne des produits les plus courants dans chaque catégorie.

${ }^{\mathrm{b}}$ Teneurs minimales et maximales de l'ensemble des denrées incluses dans les catégories retenues, selon la liste de Lassaletta et al. (2014a).

Cette hypothèse n'est nécessaire que pour le calcul de la provenance des produits au second ordre, c'est-à-dire en tenant compte des origines antérieures au dernier chargement : le flux $I_{2}$ importé au territoire $a$ depuis chaque origine $i$ est donné par la somme des contributions de cette origine dans tous les flux entrants de toutes les provenances :

$$
I_{2}(a, i)=\sum_{k \neq a}\left(F^{*}(a, k) \times r_{1}(k, i)\right),
$$

où $r_{1}(k, i)$ représente la fraction de chaque origine $i$ dans les flux apportés au territoire $k$ :

$$
r_{1}(k, i)=\frac{F^{*}(k, i)}{\sum_{j} F^{*}(k, j)} .
$$

Les résultats au second ordre ne se révèlent pas fondamentalement différents de ceux obtenus au premier ordre, ce qui relativise le biais que l'hypothèse de mélange parfait pourrait entraîner.

Par défaut, les unités de calcul utilisées par AmstraM sont des tonnes de marchandises, telles que fournies par la base SitraM. Pour l'agrégation de plusieurs types de produits agricoles, il est plus pertinent de convertir les flux dans une unité générique qui peut être la valeur calorique ou le contenu en azote protéique. Compte tenu des objectifs de notre étude, c'est ce dernier choix qui a été fait ici. Les coefficients de conversion pour chaque catégorie de la nomenclature NST ont été fixés à partir d'une liste plus détaillée compilée par Lassaletta et al. (2014a) et sont rassemblés dans le Tableau 1. Les regroupements imposés par la nomenclature, de même que la variabilité naturelle des produits, conduisent à une certaine incertitude sur les coefficients retenus. L'intervalle de variation de ces coefficients est mentionné également dans le Tableau 1.

\subsection{Regroupement de produits et de départements}

Parmi les 50 denrées agricoles renseignées dans la base SitraM, notre étude distingue les sept groupes de produits suivants :

- les céréales (froment, épeautre, méteil, orge, seigle, avoine et riz) à l'exclusion du maïs ;

- le maïs grain ;

- les fruits et légumes (regroupant pommes de terre, betteraves à sucre, légumes secs, houblon, autres légumes frais ou congelés, agrumes, autres fruits et noix frais, fruits congelés séchés ou déshydratés, préparations et conserves de fruits, préparations et conserves à base de légumes) ;

- les aliments pour animaux (paille, foin, balle de céréales, graines oléagineuses, noix, amandes oléagineuses, tourteaux et résidus de l'extraction des huiles végétales, sons et 
Tableau 2. Territoires agricoles considérés dans l'analyse des flux d'échanges et leurs principales caractéristiques agricoles. Table 2. Agricultural territories considered in the analysis of commercial fluxes, and their main characteritics.

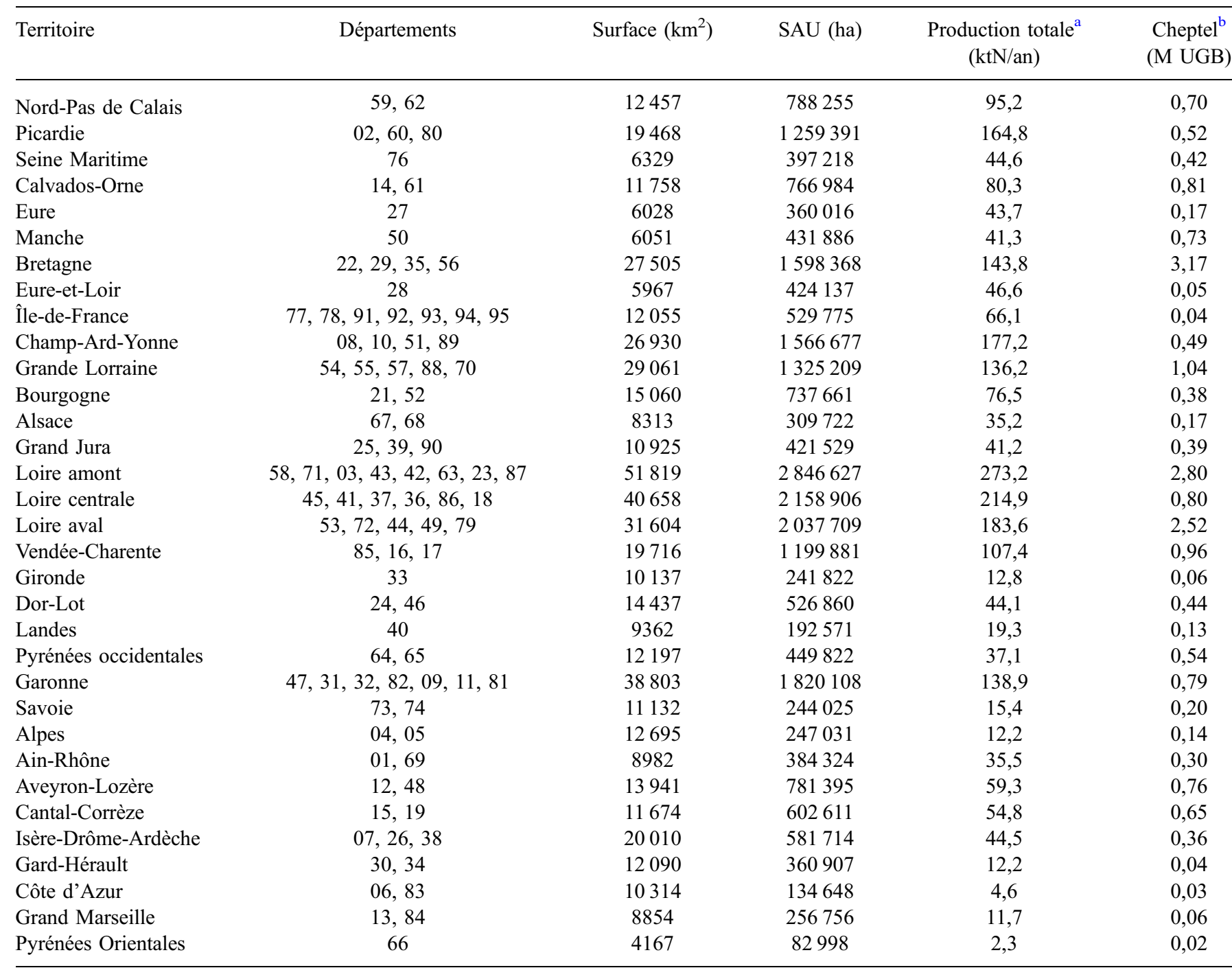

${ }^{\text {a }}$ Production végétale totale y compris la production des prairies permanentes.

${ }^{\mathrm{b}}$ Cheptel en millions d'unités gros bétail, UGB, défini arbitrairement comme produisant $85 \mathrm{kgN} / \mathrm{an}$ d'excréta.

issues, autres nourritures pour animaux, déchets des industries alimentaires) ;

- la viande (viande fraîche, réfrigérée et congelée, viande séchée, salée, fumée, préparations et conserves de viande) ;

- les produits laitiers (lait frais et crème fraîche, beurre, fromage, autres produits laitiers, œufs) ;

- les animaux vivants.

Pour améliorer la lisibilité des flux d'échange de marchandises, les 95 départements français ont été regroupés en 33 territoires agricoles, définis selon leur proximité géographique et la similitude de leur système agricole, en termes d'importance des prairies permanentes dans la SAU et de densité de cheptel (Tab. 2). Les pays étrangers, hormis les pays proches avec lesquels les échanges sont les plus importants (Belgique-Luxembourg, Pays-Bas, Allemagne, Royaume-Uni, Italie, Espagne, Portugal), ont été regroupés par (sous-)continents (autres pays d'Europe, Amérique du Nord, Amérique centrale, Amérique latine, Nouvelle-Zélande et Australie, Maghreb et Proche Orient, Afrique subsaharienne, Asie).

\subsection{La construction des matrices de flux nets d'échange}

À l'aide du logiciel AmstraM, nous avons constitué pour chacune des sept catégories de denrées une matrice $(57 \times 57)$ des importations brutes depuis les territoires agricoles français vers chaque territoire français et étranger (les flux commerciaux 


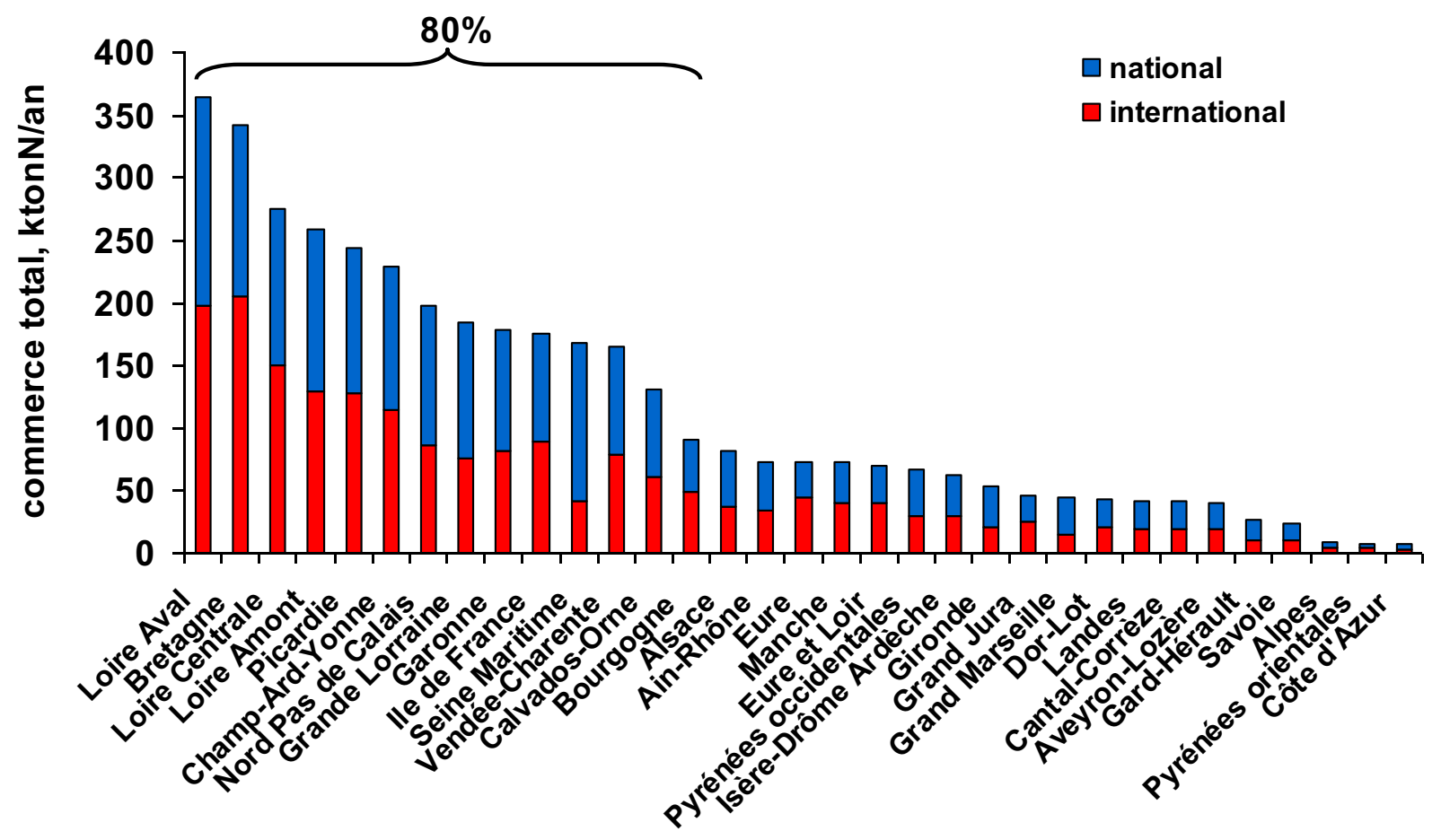

a.

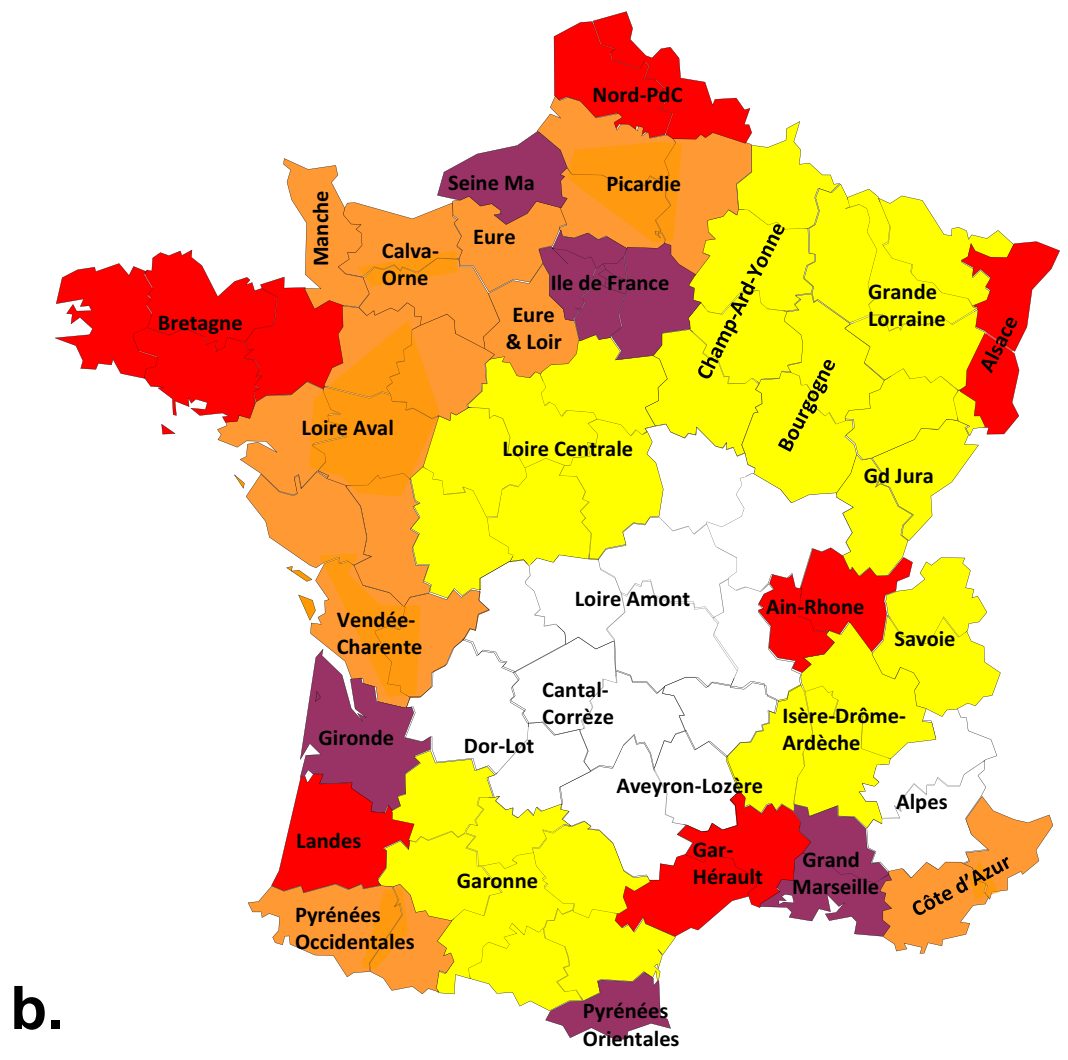

\section{Rapport commerce I production}

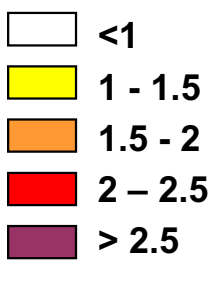

Fig. 1. a. Flux d'échanges inter-territoires et internationaux de denrées agricoles par regroupement de départements. b. Distribution spatiale du rapport entre le flux commercial longue distance et la production agricole locale (cultures et fourrage) des différents territoires agricoles.

Fig. 1. a. Inter-territorial and international exchanges of nitrogen in agricultural commodities for the different groupings of departments. b. Spatial distribution of the ratio between long distance trade and local production (crop and forage). 


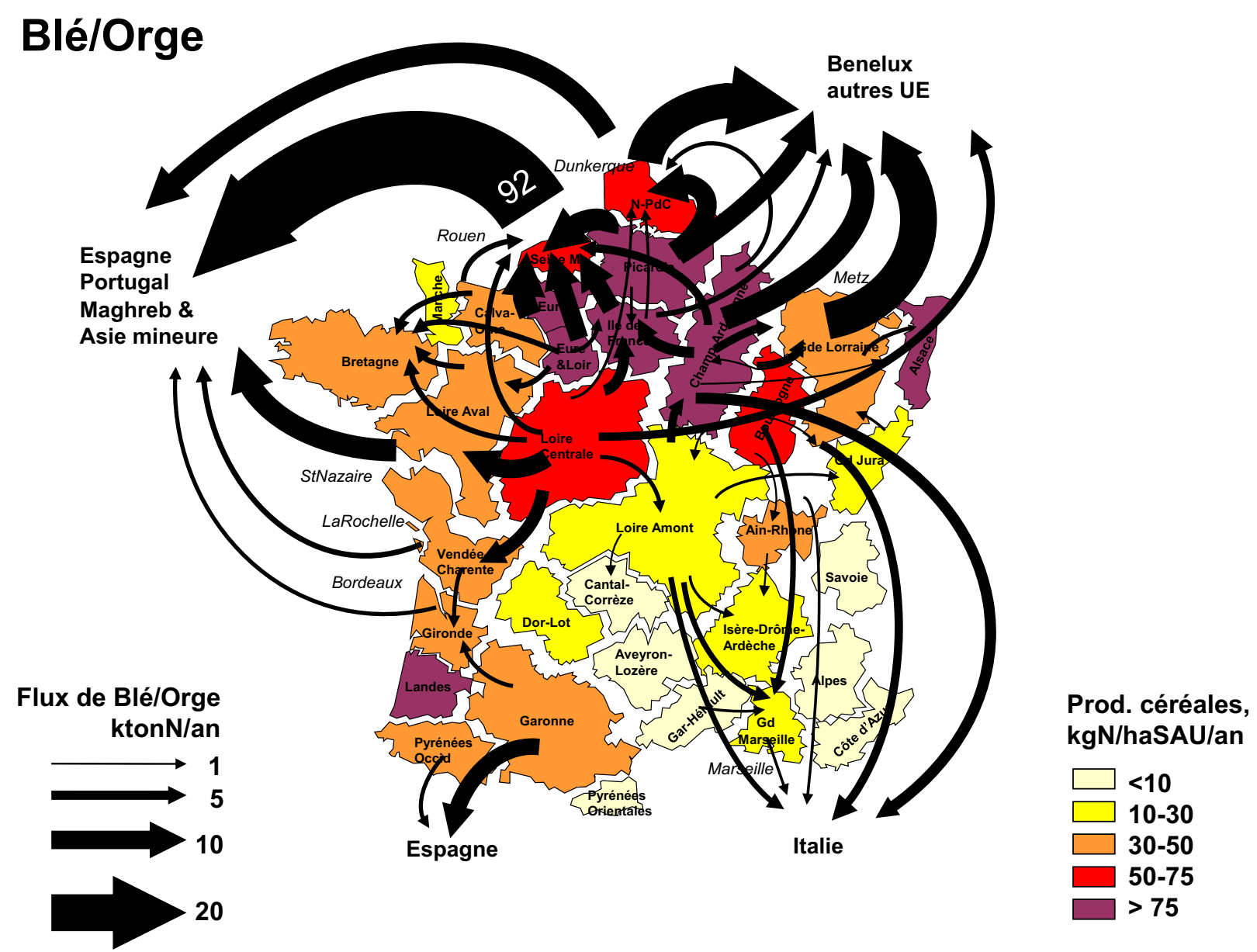

Fig. 2. Principaux flux nets de céréales (hors maïs) échangés entre territoires agricoles. L'épaisseur des flèches est proportionnelle à l'importance du flux, sauf dans le cas où le flux dépasse une valeur maximale au-delà de laquelle la valeur du flux est mentionnée explicitement. En fond de carte est indiquée par un code couleur la production de céréales par unité de SAU totale de chaque région.

Fig. 2. Main net fluxes of cereals (except maize) exchanged between agricultural territories. Unless explicitly indicated, the width of the arrows is proportional to the flux intensity. Cereal production per unit of total agricultural surface is indicated by a colour scale.

entre les pays étrangers n'ont pas été renseignés). Chaque matrice est alors transposée : les lignes devenant des colonnes, on obtient une matrice des exportations de chaque territoire vers les autres. La soustraction de la matrice transposée (exportations) à la matrice d'origine (importations) correspondante permet d'obtenir une matrice des flux nets d'échange pour chacune des sept catégories de produits.

\section{Résultats}

Les 14 matrices d'échanges bruts et d'échanges nets de céréales, maïs, fruits et légumes, aliments pour animaux, viande, produits laitiers et animaux vivants, en tonnes d'azote par an, sont disponibles sous forme de deux fichiers Excel à l'adresse http://www.metis.upmc.fr/shared information/2016/ LeNoe_et_al_Cahiers_Agricultures/Supplementary_materials. zip. Chaque fichier comporte aussi une matrice des flux d'échange bruts ou nets d'azote total, constituée par la somme algébrique de toutes les autres. Une brève analyse de ces matrices est présentée ici, notamment sous forme de cartes figurant les échanges les plus importants par des flèches d'épaisseur proportionnelle à la valeur du flux.

\subsection{Implication des territoires agricoles dans les échanges}

L'analyse des flux bruts d'échanges inter-territoriaux et internationaux révèle une participation très contrastée des territoires au commerce de denrées agricoles. Comme le montre la Figure 1a, $80 \%$ des échanges impliquent seulement $45 \%$ des territoires.

Les flux commerciaux sont ici définis à partir de la matrice des flux bruts en cumulant pour chaque territoire ses importations et exportations de toutes denrées depuis et vers les autres territoires (commerce interrégional) et depuis ou vers l'étranger (commerce international), puis en divisant par deux ce cumul, de manière à corriger un double compte des flux entre territoires. Le rapport de ces flux avec la production agricole totale de chaque territoire (Tab. 2 et Fig. 2b) offre un indicateur du degré d'ouverture de son système agro-alimentaire. Un contraste très net apparaît alors (Fig. 1b) entre les régions des façades atlantique et méditerranéenne (ainsi que les autres territoires à forte population tels que l'Alsace et la région lyonnaise) d'une part, et ceux du centre du pays d'autre part, qui restent à l'écart des grands échanges commerciaux. 


\section{Maïs}

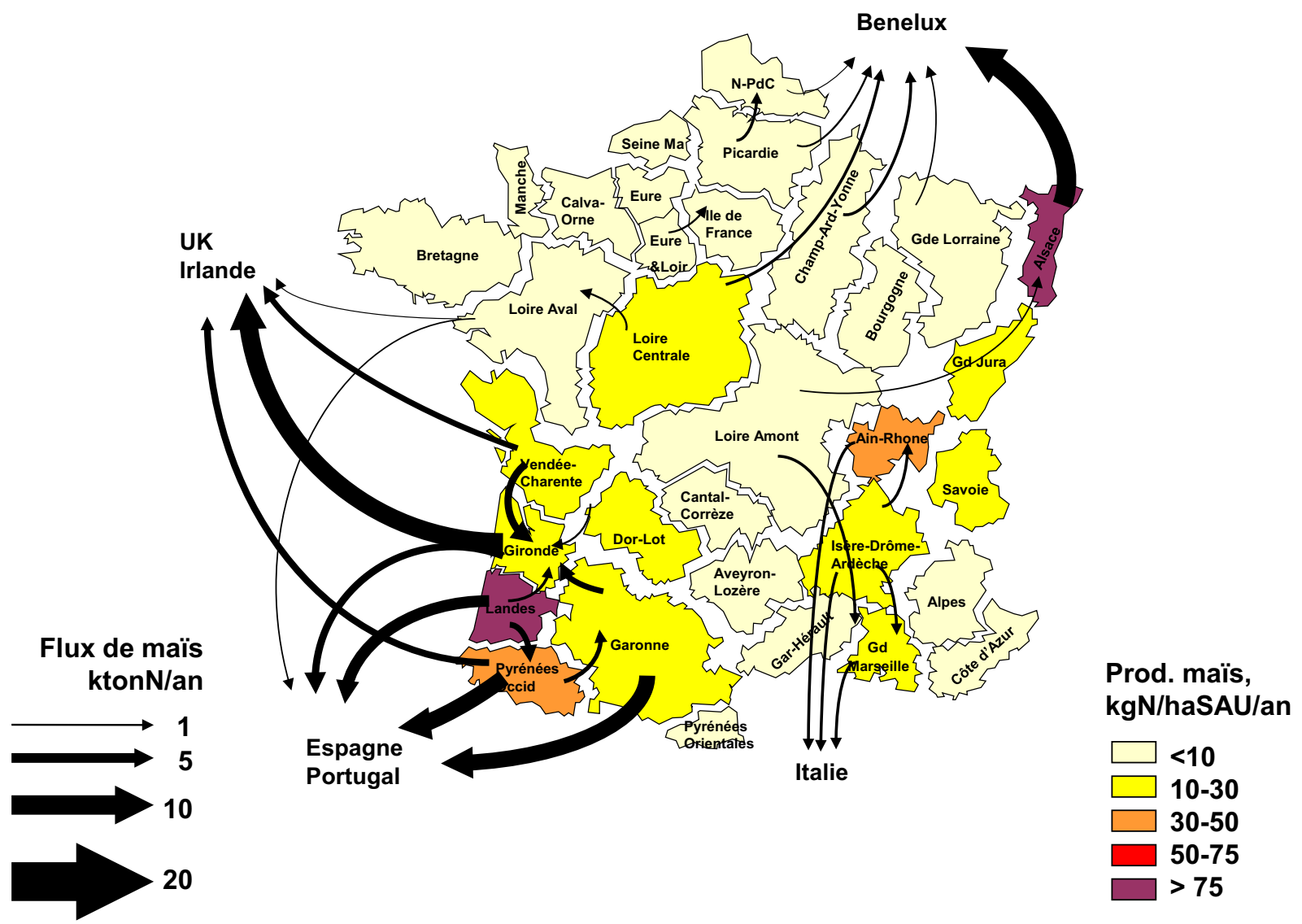

Fig. 3. Principaux flux nets de maïs échangés entre territoires agricoles. L'épaisseur des flèches est proportionnelle à l'importance du flux. En fond de carte est indiquée par un code couleur la production de maïs par unité de SAU totale de chaque région.

Fig. 3. Main net fluxes of maize exchanged between agricultural territories. The width of the arrows is proportional to the flux intensity. Maize production per unit of total agricultural surface is indicated by a colour scale.

À l'échelle nationale, les flux d'azote associés aux échanges de denrées agricoles correspondent à 1,6 fois la production agricole totale (en tonne d'azote).

\subsection{Les flux de céréales}

La France exporte, en flux bruts, 44 fois plus de céréales (hors maïs) qu'elle n'en importe : $252 \mathrm{ktN} / \mathrm{an}$ sont exportés (principalement vers le Maghreb et l'Asie mineure, l'Europe du Nord, la péninsule Ibérique et l'Italie) pour une production totale de $879 \mathrm{ktN}$ en 2006. Ces exportations ont lieu pour la plus grande partie au départ des ports maritimes (Rouen, Dunkerque, Saint-Nazaire, La Rochelle, Bordeaux, Marseille) ou fluviaux (Metz), vers lesquels convergent les flux en provenance des grandes plaines céréalières du bassin parisien (Fig. 2).

Pour le maïs grain, dont les principales aires de production sont centrées sur l'Alsace, la vallée du Rhône et le Sud-Ouest, les mêmes caractéristiques s'observent, avec un tiers de la production ( 84 pour $232 \mathrm{ktN} / \mathrm{an}$ ) exportée à l'étranger (Fig. 3).

\subsection{Les flux de viande et de produits laitiers}

La représentation cartographique des flux de viande (Fig. 4) fait apparaître le rôle majeur que jouent les territoires $\mathrm{du}$ « Grand Ouest » (Bretagne, Loire aval et Manche) dans l'approvisionnement en viande de l'ensemble des territoires français, et tout particulièrement l'Île-de-France et la région voisine de la Loire aval. Pour une production nationale totale de $160 \mathrm{ktN} / \mathrm{an}$, la Bretagne et la Loire aval exportent à elles seules $60 \mathrm{ktN} / \mathrm{an}$, principalement vers les autres régions françaises ou le Nord de l'Europe. Les autres flux d'échange sont beaucoup plus limités, sauf ceux issus de la Garonne vers l'étranger et ceux du Nord de l'Europe vers l'île-deFrance.

Si la France est exportatrice nette de produits laitiers (à raison de $23 \mathrm{ktN} / \mathrm{an}$ pour une production de $115 \mathrm{ktN} / \mathrm{an}$ ), les flux d'échange entre territoires français dominent cependant nettement (Fig. 5). La Bretagne et la Manche sont les plus gros pourvoyeurs des autres régions, tandis que l'Île-de-France concentre vers elle des flux considérables issus à la fois du Grand Ouest, de l'Est et du Centre de la France. 


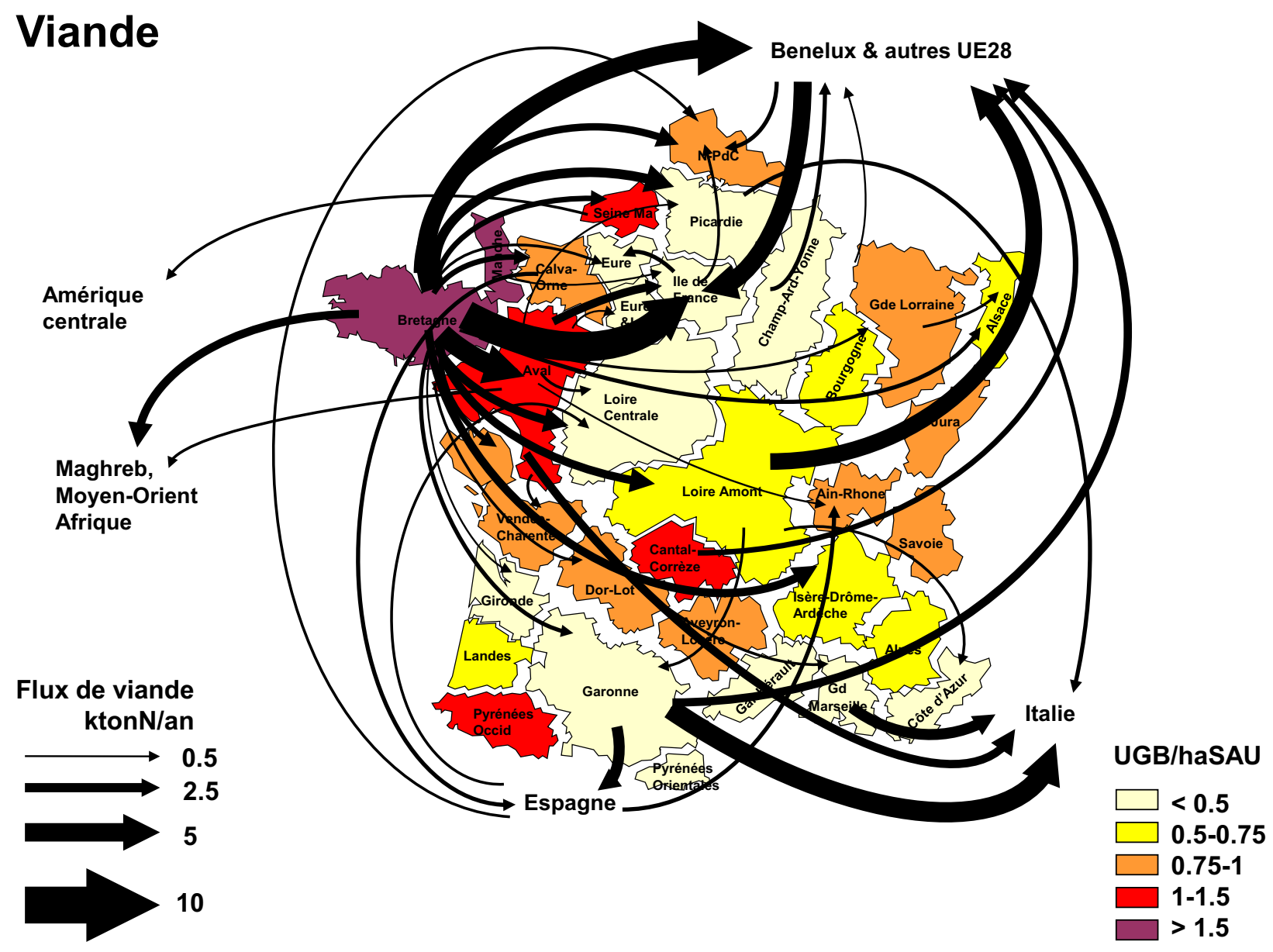

Fig. 4. Principaux flux nets de viande échangés entre territoires agricoles. L'épaisseur des flèches est proportionnelle à l'importance du flux. En fond de carte est indiquée par un code couleur la densité du cheptel par unité de SAU totale de chaque région.

Fig. 4. Main net fluxes of meat exchanged between agricultural territories. The width of the arrows is proportional to the flux intensity. Livestock density per unit of total agricultural surface is indicated by a colour scale.

Les flux nets d'azote associés aux flux d'animaux vivants entre régions françaises sont faibles, et le sont encore davantage vers l'étranger. Le solde de ces derniers montre une exportation nette de $6,3 \mathrm{ktN} / \mathrm{an}$ d'animaux vivants.

\subsection{Les flux d'aliments pour animaux}

La spécialisation territoriale de l'agriculture française donne lieu à des transferts importants de produits destinés à l'alimentation animale, tels que les tourteaux de colza ou de tournesol, depuis les régions de grande culture vers les régions d'élevage au sein du territoire national ou européen (Fig. 6). Les flux inter-régionaux (estimés ici à $156 \mathrm{ktN} / \mathrm{an}$ ) sont cependant bien plus faibles que les flux nets d'importation d'aliments pour bétail depuis l'étranger (284 ktN/an), principalement du soja (en graine et en tourteaux) du Brésil et d'Argentine. Sans surprise, c'est la Bretagne et la Loire aval qui concentrent les plus gros flux d'importation d'aliments pour animaux, mais toutes les régions d'élevage sont concernées, de même que celles, comme l'Île-de-France, qui abritent des industries de conditionnement d'aliments pour bétail.

\subsection{Les fruits et légumes}

Cette dernière catégorie regroupe un peu artificiellement des produits agricoles tels que la betterave, la pomme de terre, les légumes, dont les zones de production sur le territoire français sont surtout localisées dans le Nord, et les fruits, produits surtout dans le Sud et à l'étranger. Destinés essentiellement à la consommation humaine, les transferts de ces produits se concentrent vers les régions très peuplées, telles que l'Île-de-France, la région lyonnaise et le Grand Marseille (Fig. 7). À l'échelle nationale, le total des importations de fruits et légumes depuis l'étranger représente $22 \mathrm{ktN} / \mathrm{an}$, pour des exportations de $36 \mathrm{ktN} / \mathrm{an}$, soit un solde exportateur de $14 \mathrm{ktN} / \mathrm{an}$. Les productions légumières du nord de la France sont surtout exportées vers les pays du Maghreb, le MoyenOrient et l'Asie mineure, alors que les fruits produits au Sud de la France sont acheminés plutôt vers l'Italie.

\subsection{Flux totaux de protéines}

La somme des flux d'azote associés aux différents produits agricoles fournit une image synthétique des échanges entre 


\section{Produits laitiers}

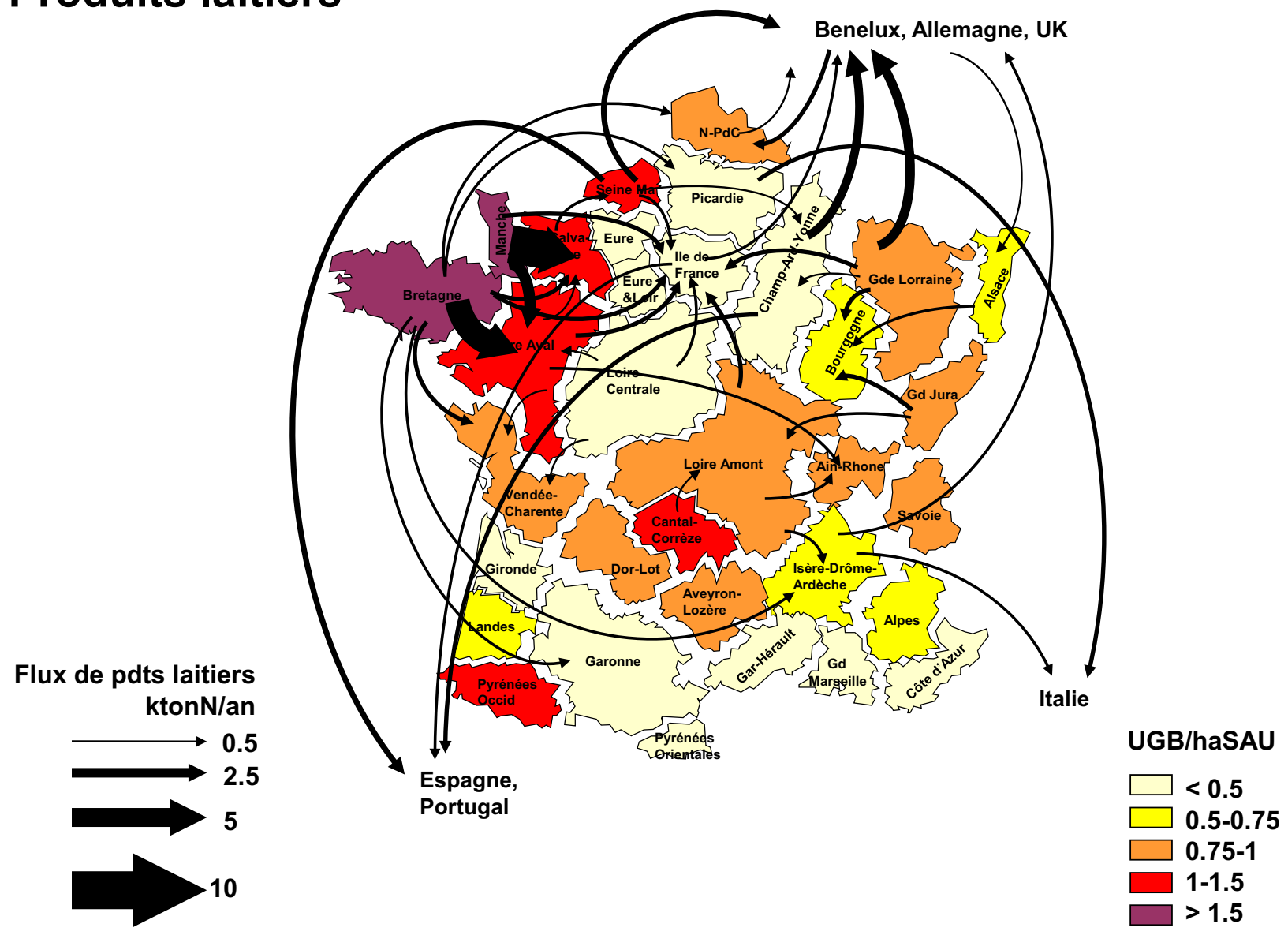

Fig. 5. Principaux flux nets de produits laitiers échangés entre territoires agricoles. L'épaisseur des flèches est proportionnelle à l'importance du flux. En fond de carte est indiquée par un code couleur la densité du cheptel par unité de SAU totale de chaque région.

Fig. 5. Main net fluxes of milk products exchanged between agricultural territories. The width of the arrows is proportional to the flux intensity. Livestock density per unit of total agricultural surface is indicated by a colour scale.

territoires et avec l'étranger. Globalement, la France apparaît comme exportatrice nette du point de vue de ses échanges de protéines avec l'étranger, important $284 \mathrm{ktN} / \mathrm{an}$ d'aliments pour bétail et exportant $390 \mathrm{ktN} / \mathrm{an}$ sous forme de céréales, de fruits et légumes et de produits animaux (Tab. 3). L'importation de graines et de tourteaux de soja du Brésil et d'Argentine constitue la plus grande partie des importations nettes de protéines, qui alimentent l'élevage dans toute la moitié Ouest du pays. Les exportations de protéines sont pour leur part largement dominées par les céréales à destination du Maghreb et de l'Asie Mineure, de l'Europe du Nord et de l'Europe méditerranéenne (Fig. 8). On peut clairement distinguer dans le pays des territoires importateurs nets de protéines (territoires hétérotrophes, au sens de Billen et al., 2010), exportateurs nets (territoires autotrophes) ou équilibrés. Les territoires importateurs nets le sont soit à cause de leur spécialisation dans l'élevage (le Grand Ouest), soit à cause d'une concentration de population très importante (Îlede-France, région lyonnaise, Marseille-Côte d'Azur, Gironde). Parmi les territoires les plus autotrophes, on trouve ceux du bassin parisien et du bassin aquitain, ainsi que le Nord et l'Alsace.

\section{Discussion}

\subsection{Potentialités et limites de la méthode}

Si les données de la base SitraM ont déjà été exploitées pour calculer les flux de matériaux (Barles, 2014), les résultats présentés ici sont à notre connaissance les premiers issus de l'exploitation de cette base avec l'objectif de caractériser l'agriculture française. Leur croisement avec les statistiques annuelles de la production agricole ne va pas sans quelques difficultés méthodologiques qu'il convient de garder à l'esprit. Une première difficulté résulte de la différence des nomenclatures utilisées dans les deux bases de données. Cela oblige à des regroupements de produits et, par la suite, à la conversion en une unité commune sujette à des incertitudes dont l'ampleur, mesurée par l'intervalle de variation des teneurs en azote de chaque denrée, est de l'ordre de $20 \%$ (Tab. 1). La base SitraM elle-même n'est pas exempte de biais ; ses données proviennent de sources diverses selon le mode de transport, dont la plus importante, celle relative au transport routier, repose sur des enquêtes non exhaustives à partir desquelles l'extrapolation est parfois incertaine. 


\section{Aliments pour animaux}

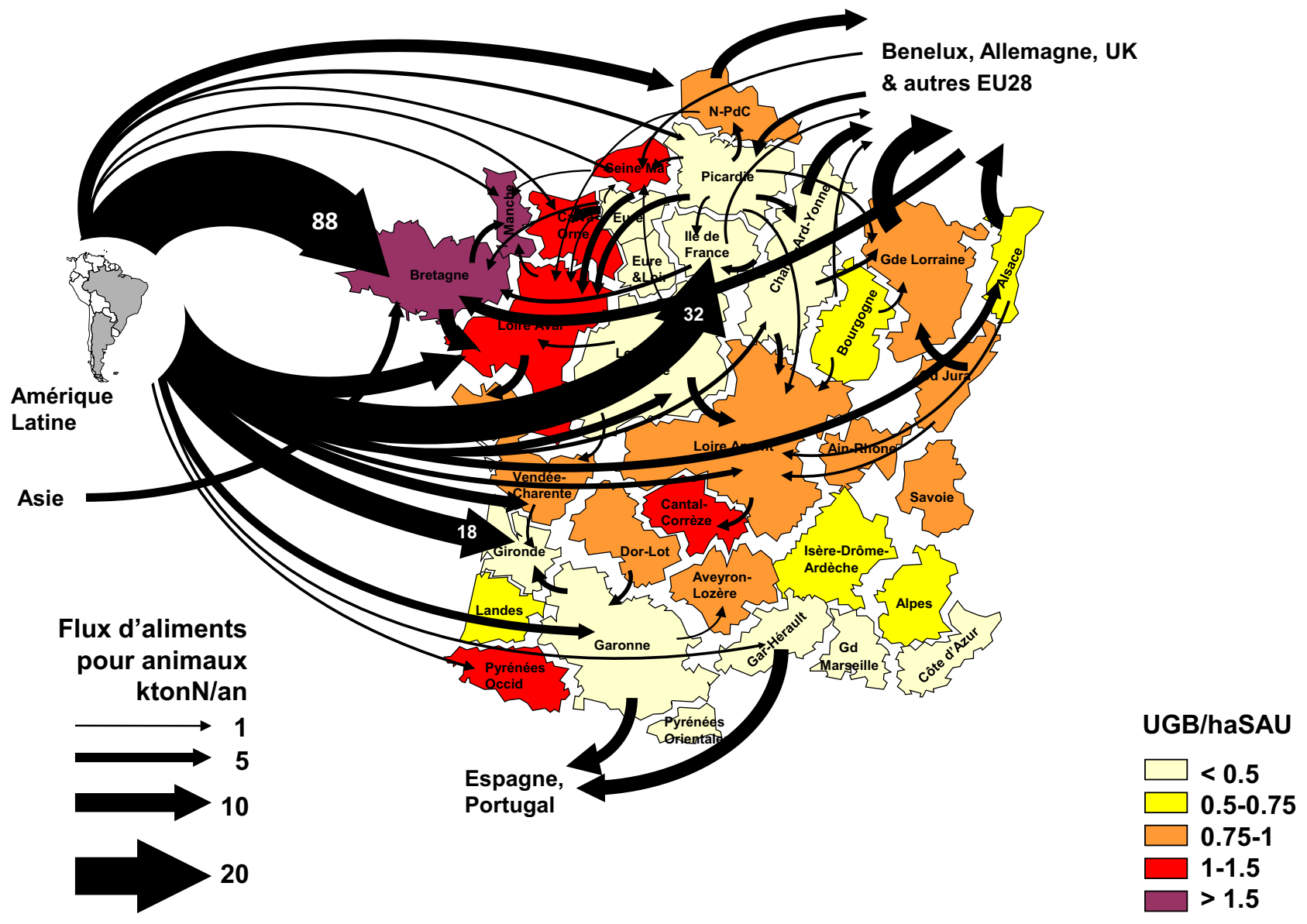

Fig. 6. Principaux flux nets d'aliments pour animaux échangés entre territoires agricoles. Sauf mention explicite, l'épaisseur des flèches est proportionnelle à l'importance du flux. En fond de carte est indiquée par un code couleur la densité du cheptel par unité de SAU totale de chaque région.

Fig. 6. Main net fluxes of feed exchanged between agricultural territories. Unless explicitly indicated, the width of the arrows is proportional to the flux intensity. Livestock density per unit of total agricultural surface is indicated by a colour scale.

Les fluctuations du prix des denrées agricoles peuvent aussi induire un découplage entre production et transport du fait des stockages intermédiaires, surtout à l'échelle internationale. Pour des produits comme les céréales, la capacité de stockage est en effet considérable ; rien que dans les infrastructures portuaires, elle atteint 3150000 tonnes (www.haropaports.com), soit $5 \%$ de la production annuelle nationale.

Malgré ces difficultés, le calcul des flux nets d'échange de produits agricoles entre régions françaises et avec l'étranger offre une image d'ensemble très cohérente du fonctionnement du système agro-alimentaire national et de sa spécialisation territoriale.

\subsection{Grands zonages géographiques de la France}

L'examen des cartes de flux commerciaux de produits agricoles entre régions permet d'individualiser cinq grands ensembles de territoires du point de vue de l'ampleur et de la destination des échanges qui y prennent place.
Ainsi, un grand quart Nord-Ouest de la France, couvrant le bassin parisien, le Nord-Pas de Calais, la Bretagne et les Pays de Loire, est clairement le siège de la plus grande partie des échanges nationaux et internationaux. Soixante pour cent des échanges recensés y ont lieu, dont $49 \%$ entre régions et $51 \%$ avec l'étranger. Cet espace avait déjà été identifié par Billen et al. (2012) comme l'aire principale d'approvisionnement de l'agglomération parisienne, fournissant $70 \%$ des denrées consommées en Île-de-France. Il est constituée de deux sousensembles territoriaux aux orientations productives diamétralement opposées : l'un de grande culture centré sur le bassin parisien, et l'autre spécialisé en élevage comprenant la Bretagne, la Loire aval et la Manche. Si cette spécialisation donne lieu à des flux d'échanges importants entre ces deux sous-ensembles, il n'en demeure pas moins que les flux internationaux prennent une part tout à fait dominante dans leurs fonctionnements respectifs. Les exportations de céréales du bassin parisien, vers le Maghreb, l'Asie Mineure et l'Europe $\mathrm{du}$ Nord dépassent très largement les transferts vers le Grand Ouest; de même les importations d'aliments pour bétail en provenance d'Amérique latine vers les zones d'élevage sont 


\section{Fruits et légumes}

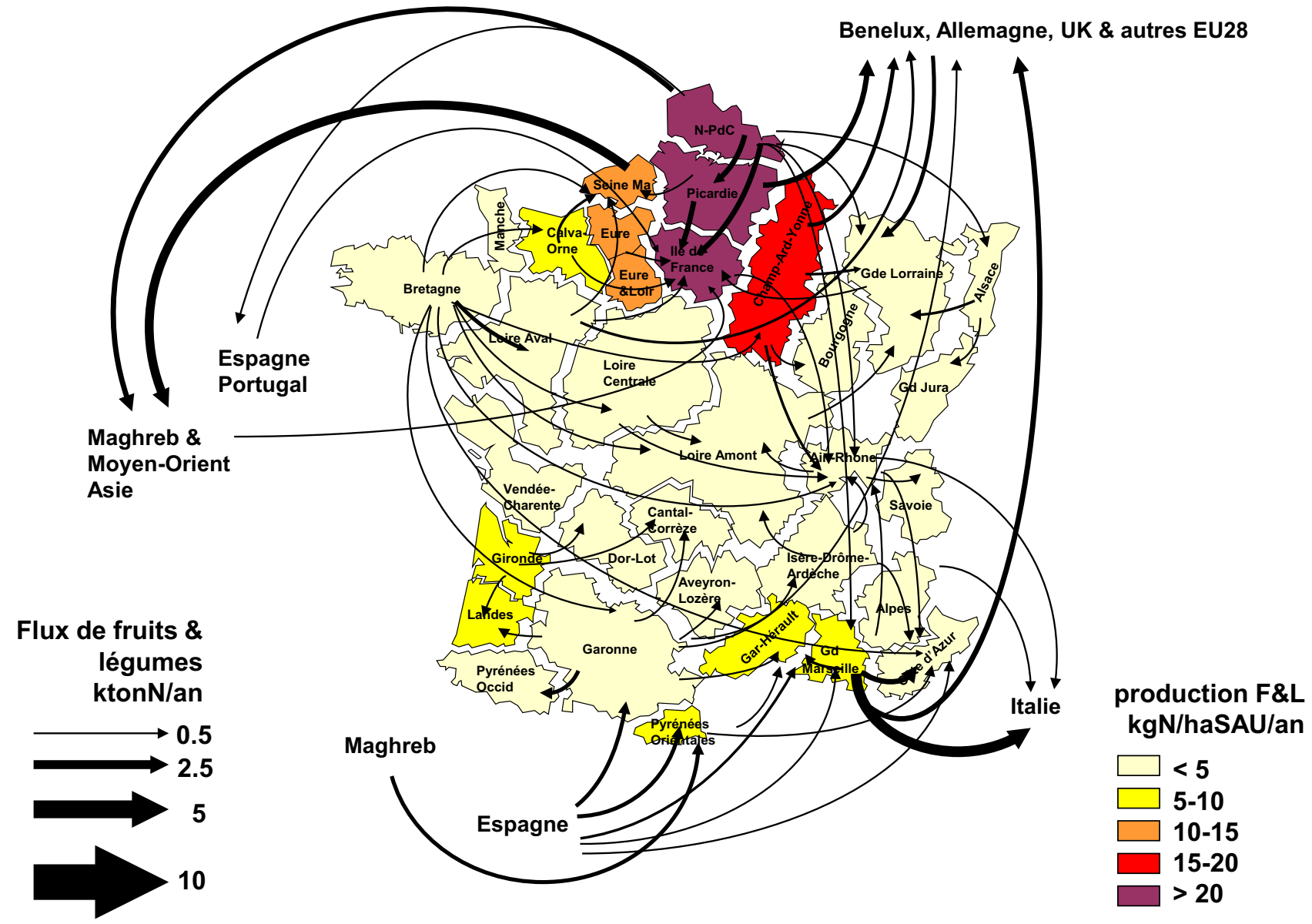

Fig. 7. Principaux flux nets de fruits et légumes échangés entre territoires agricoles. L'épaisseur des flèches est proportionnelle à l'importance du flux. En fond de carte est indiquée par un code couleur la production de fruits et légumes par unité de SAU totale de chaque territoire.

Fig. 7. Main net fluxes of fruits and vegetables exchanged between agricultural territories. The width of the arrows is proportional to the flux intensity. Fruits and vegetable production per unit of total agricultural surface is indicated by a colour scale.

Tableau 3. Importations et exportations brutes, et solde net de protéines contenues dans les denrées alimentaires (en ktN/an) au niveau national en 2006.

Table 3. Gross imports and exports, and net balance of proteins imbedded in food and feed (in kton N/yr) at national scale in 2006.

\begin{tabular}{lccr}
\hline Denrées agricoles & $\begin{array}{c}\text { Importations brutes } \\
(\mathrm{ktN} / \mathrm{an})\end{array}$ & $\begin{array}{c}\text { Exportations brutes } \\
(\mathrm{ktN} / \mathrm{an})\end{array}$ & $\begin{array}{c}\text { Exportations }- \text { importations } \\
(\mathrm{ktN} / \mathrm{an})\end{array}$ \\
\hline Céréales (hors maïs) & 12,0 & 258,3 & 246,3 \\
Maïs & 3,8 & 88,4 & 84,4 \\
Fruits et légumes & 21,6 & 35,5 & 13,9 \\
Aliments pour animaux & 400,4 & 116,5 & $-283,8$ \\
Animaux vivants & 0,7 & 7,0 & 6,3 \\
Viande & 52,3 & 68,5 & 16,2 \\
Produits laitiers & 38,5 & 61,6 & 23,1 \\
Toutes denrées & 529,6 & 636,0 & 106,4 \\
\end{tabular}

sans commune mesure avec les flux de produits fourragers issus des zones de grande culture du bassin parisien vers ces mêmes zones. Même si la viande et le lait produits dans le Grand Ouest sont principalement destinés à un marché national, la logique de développement des deux zones n'est clairement pas basée sur leurs complémentarités potentielles, mais plutôt sur une intégration centrifuge vers les marchés internationaux. 


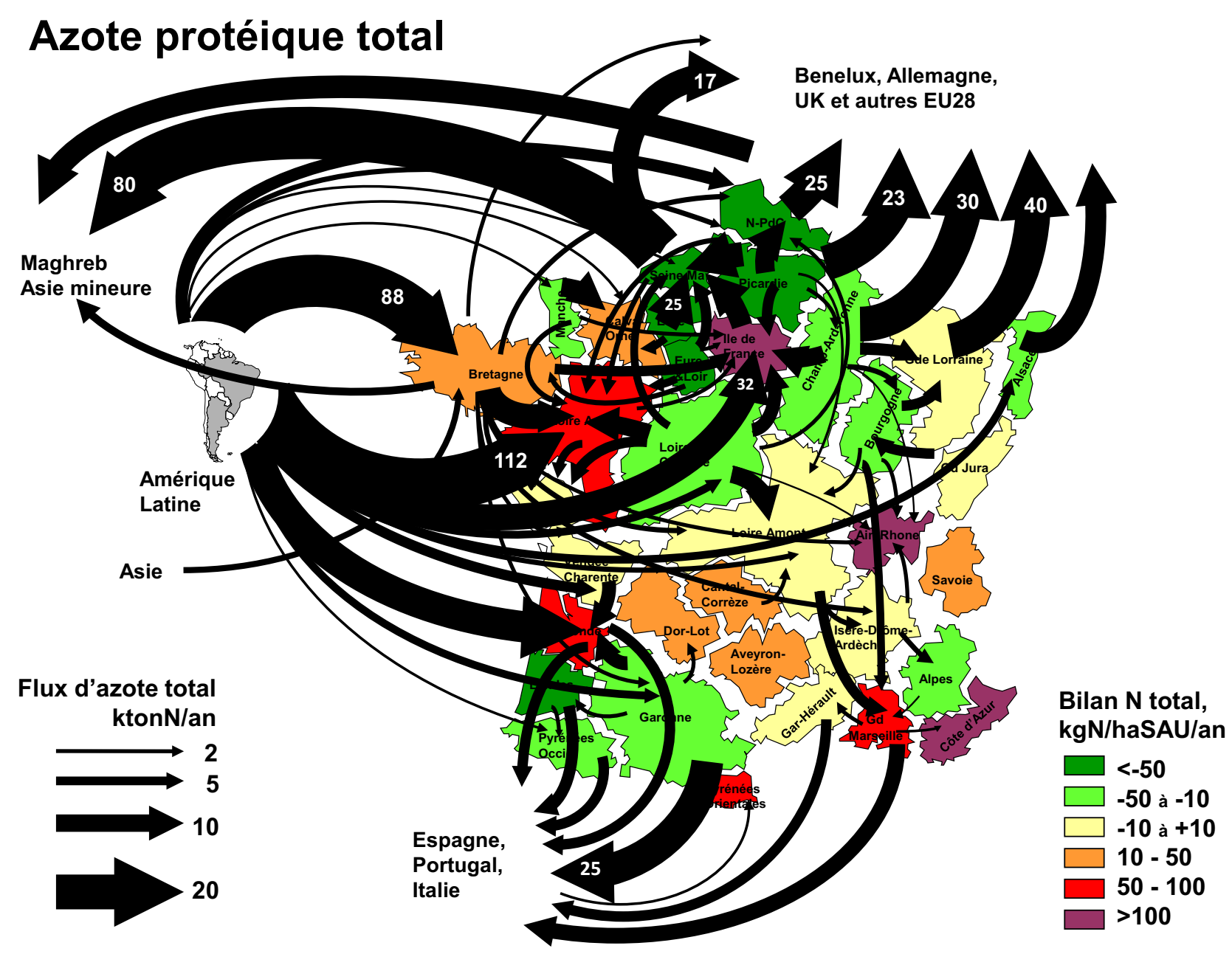

Fig. 8. Principaux flux nets d'azote total contenu dans les denrées agricoles entre territoires agricoles. Sauf mention explicite, l'épaisseur des flèches est proportionnelle à l'importance du flux, mais seuls les flux supérieurs à $2 \mathrm{ktN} / \mathrm{an}$ sont représentés. En fond de carte est indiqué par un code couleur le bilan des échanges nets d'azote alimentaire par unité de SAU totale de chaque région.

Fig. 8. Main net fluxes of total protein nitrogen in agricultural commodities exchanged between agricultural territories. Unless explicitly stated, the width of the arrows is proportional to the flux intensity, but only fluxes higher than $2 \mathrm{ktonN} / \mathrm{yr}$ are represented. Total protein production per unit of total agricultural surface is indicated by a colour scale.

Le Nord-Est de la France (Alsace, Grande Lorraine, Bourgogne, Jura et dans une moindre mesure ChampagneArdenne-Yonne) semble se distinguer quelque peu de ce grand ensemble bi-polaire très actif du Nord-Ouest. Ici les exportations sont surtout tournées vers l'Europe du Nord. Le port fluvial de Metz y joue un grand rôle. Le maïs occupe une place importante dans les cultures d'exportation. L'élevage, pourtant bien développé, y dépend beaucoup moins d'importations lointaines d'aliments pour bétail que dans les régions du Grand Ouest.

La vallée du Rhône structure nettement les échanges agricoles des régions d'un petit quart Sud-Est de la France. Lyon et Marseille, mais aussi la Côte d'Azur, constituent des centres de consommation alimentaire importants, approvisionnés par des origines très diverses, mais où dominent les territoires limitrophes du Sud-Est (45 \% des importations vers Ain-Rhône, Grand Marseille et Côte d'Azur) par rapport aux importations des autres départements français ou d'Espagne et du Maghreb. Les rares exportations internationales à partir de cet ensemble territorial (maïs, viande, aliments pour animaux) sont principalement à destination de l'Espagne ou de l'Italie.

Enfin le Sud-Ouest, de la Vendée-Charente à la Garonne, est caractérisé par des échanges mutuels importants, mais aussi par un commerce international actif, où dominent les exportations de maïs et de viande vers la péninsule ibérique. Les importations de soja sud-américain y sont également très importantes.

À l'écart des flux commerciaux dominants, les régions du Massif Central échangent assez peu avec leur voisines.

\subsection{La mobilité des denrées agricoles et la cascade de l'azote}

L'intérêt de l'approche biogéochimique de la chaîne agroalimentaire, dans laquelle le fonctionnement du système est 
traduit en flux d'azote, réside dans la possibilité de faire le lien entre sa fonction productrice d'aliments (protéines) et les pertes environnementales auxquelles elle donne lieu. Ces dernières alimentent une cascade de transferts et de transformations qui contaminent gravement l'hydrosphère, l'atmosphère et la pédosphère (Galloway et al., 2003, 2008 ; Sutton et al., 2011). La grande mobilité de l'azote dans l'environnement, liée à la fois à la solubilité des nitrates dans l'eau et à l'existence des formes gazeuses que sont l'ammoniac et les oxydes d'azote, explique l'importance et l'ubiquité des effets induits par les fuites agricoles. Notre analyse révèle en outre l'ampleur d'une mobilité d'une autre nature, liée au transport commercial de denrées agricoles. Les flux d'azote sous forme de produits agricoles transportés entre territoires (c'est-à-dire à plus d'une centaine de kilomètres de leur lieu de production) et avec l'étranger représentent 1,6 fois la production agricole totale. Le rapport des flux d'échanges à la production agricole locale varie selon les régions de 0,7 (Aveyron-Lozère) à plus de 3 (Seine Maritime, Île-de-France, Grand Marseille, Gironde). L'ouverture du cycle de l'azote associé à l'activité agricole n'est donc pas seulement une affaire de pratiques agricoles, c'est aussi la conséquence d'un système agro-alimentaire spatialement très spécialisé et très tourné vers le commerce à longue distance, sans recherche de complémentarités fonctionnelles entre territoires proches, qui permettrait de mieux assurer le bouclage du cycle de l'azote. Le cas de la France montre que la spécialisation de la production agricole et les interdépendances observées au niveau global entre les différentes parties du monde (Billen et al., 2014) se retrouvent à l'échelle des territoires français.

\section{Conclusion}

L'analyse que nous livrons ici de la base de données SitraM sur le transport inter-départemental des denrées alimentaires offre une vision inédite du fonctionnement du système agroalimentaire français, de sa spécialisation territoriale et de sa dépendance vis-à-vis de l'étranger, tant pour l'approvisionnement en protéines destinées à l'alimentation du bétail que pour l'exportation de ses céréales. Le développement des échanges longue distance $(>100 \mathrm{~km})$ de produits agricoles, qui dépasse aujourd'hui de $60 \%$ la production agricole, s'ajoute à la mobilité de l'azote et contribue ainsi à des transformations et transferts en cascades à l'origine de la contamination de l'atmosphère et de l'hydrosphère.

\section{Références}

Bai ZH, Ma L, Qin W, Chen Q, Oenema O, Zhang FS. 2014. Changes in pig production in China and their effects on nitrogen and phosphorus use and losses. Environ. Sci. Technol. 48: 12742. doi:10.1088/1748-9326/10/4/045002.

Barles S. 2014. L'écologie territoriale et les enjeux de la dématérialisation des sociétés : l'apport de l'analyse des flux de matières. Dev. Durable Territoires 5. URL : http://developpementdurable.revues. org/10090. doi:10.4000/developpementdurable.10090 (mis en ligne le 04 février 2014, consulté le 08 décembre 2014).

Billen G, Garnier J, Mouchel J-M, Silvestre M. 2007. The Seine System: introduction to a multidisciplinary approach of the functioning of a regional river system. Sci. Total Environ. 375: $1-12$.

Billen G, Barles S, Garnier J, Rouillard J, Benoit P. 2009. The foodprint of Paris: long-term reconstruction of the nitrogen flows imported into the city from its rural hinterland. Reg. Environ. Change 9: 13-24.

Billen G, Beusen A, Bouwman L, Garnier J. 2010. Anthropogenic nitrogen autotrophy and heterotrophy of the world's watersheds: past, present, and future trends. Global Biogeochem. Cycles 24: GB0A11. doi:10.1029/2009GB003702.

Billen G, Barles S, Chatzimpiros P, Garnier J. 2012. Grain, meat and vegetables to feed Paris: where did and do they come from? Localising Paris food supply areas from the eighteenth to the twenty-first century. Reg. Environ. Changes 12: 325-336.

Billen G, Garnier J, Lassaletta L. 2013a. The nitrogen cascade from agricultural soils to the sea: modelling $\mathrm{N}$ transfers at regional watershed and global scales. Philos. Trans. R. Soc. B 368: 20130123. http://dx.doi.org/10.1098/rstb.2013.0123.

Billen G, Garnier J, Benoît M, Anglade J. 2013b. La cascade de l'azote dans les territoires de grande culture du Nord de la France. Cah. Agric. 22: 272-281. doi:10.1684/agr.2013.0640.

Billen G, Lasseletta L, Garnier J. 2014. A biogeochemical view of the global agro-food system: Nitrogen flows associated with protein production, consumption and trade. Global Food Secur. 3: 209-219. http://dx.doi.org/10.1016/j.gfs.2014.08.003i.

Billen G, Lassaletta L, Garnier J. 2015. A vast range of opportunities for feeding the world in 2050: trade-off between diet, $\mathrm{N}$ contamination and international trade. Environ. Res. Lett. 10: 025001 .

Burke M, Oleson K, McCullough E, Gaskell J. 2009. A global model tracking water, nitrogen, and land inputs and virtual transfers from industrialized meat production and trade. Environ. Model. Assess. 14: 179-193.

Caro D, LoPresti A, Davis SJ, Bastianoni S, Caldeiram K. 2014. CH 4 and $\mathrm{N} 2 \mathrm{O}$ emissions embodied in international trade of meat. Environ. Res. Lett. 9: 114005.

Desriers M. 2007. L'agriculture française depuis cinquante ans : des petites exploitations familiales aux droits à paiement unique. Agreste Cahiers $\mathrm{n}^{\circ} 2$. Accessible en ligne à l'adresse : http:// agreste.agriculture.gouv.fr/IMG/pdf/articles07072A1.pdf.

Galloway JN, Aber JD, Erisman JW, et al. 2003. The nitrogen cascade. Bioscience 53: 341-356.

Galloway JN, Townsend AR, Erisman JW, et al. 2008. Transformation of the nitrogen cycle: recent trends, questions, and potential solutions. Science 320: 889-892.

Lassaletta L, Billen G, Grizzetti B, Garnier J, Leach AM, Galloway JM, 2014a. Food and feed as a driver in the global nitrogen cycle: 50-year trends. Biogeochemistry 118: 225-241.

Lassaletta L, Billen G, Romero E, Garnier J, Aguilera E, 2014b. How changes in diet and trade patterns have shaped the $\mathrm{N}$ cycle at the national scale: Spain (1961-2009). Reg. Environ. Change 14: 785-797.

Lassaletta L, Aguilera E, Sanz-Cobena A, et al. 2014c. Leakage of nitrous oxide emissions within the Spanish agro-food system in 1961-2009. Mitigation Adapt. Strateg. for Global Change. doi:10.1007/s11027-014-9569-0.

MacDonald GK, Brauman KA, Sun S, et al. 2015. Rethinking agricultural trade relationships in an era of globalization. BioScience. doi:10.1093/biosci/biu225.

Naylor R, Steinfeld H, Falcon W, et al. 2005. Losing the links between livestock and land. Science 310: 1621-1622.

Secrétariat d'État à la Santé. 2012. Abandons de captages utilisés pour la production d'eau destinée à la consommation humaine, bilan 
Direction Générale de la Santé, Sous-direction de la prévention des risques liés à l'environnement et à l'alimentation - Février 2012. http://www.sante.gouv.fr/IMG/pdf/bil0212.pdf.

Silvestre M, Billen G, Garnier J, 2015. Évaluation de la provenance des marchandises consommées par un territoire : AmstraM, une application de webmapping basée sur les statistiques de transport et de production. In: Junqua $\mathrm{G}$, Brullot $\mathrm{S}$, eds. Écologie industrielle et territoriale : COLEIT 2012. Paris: Presses des Mines, pp. 361-370.

Sutton M, Howard C, Erisman JW, et al. 2011. The European Nitrogen Assessment: sources, effects and policy perspectives. Cambridge University Press, $601 \mathrm{p}$.

Cite this article as: Le Noë J, Billen G, Lassaletta L, Silvestre M, Garnier J. 2016. La place du transport de denrées agricoles dans le cycle biogéochimique de l'azote en France : un aspect de la spécialisation des territoires. Cah. Agric. 25: 15004. 